\title{
Testing the Weak Form State of Market Efficiency: An Empirical Evidence of Sharī'ah Compliant Index
}

\author{
Naveed ul Hassan ${ }^{1 *}$, Hafiz Zafar Ahmad ${ }^{2}$ \\ ${ }^{1}$ Department of Management Science, Virtual University, Lahore, Pakistan \\ ${ }^{2}$ Hailey College of Commerce, University of the Punjab, Lahore, Pakistan
}

\section{Keywords \\ EMH \\ Weak Form Efficiency \\ KMI-30 \\ Variance Ratio Test \\ BDS Test}

Received: 02 September 2019

Accepted: 07 September 2020

\begin{abstract}
The Efficient Market Hypothesis (EMH) proposed by Fama is considered a central premise to explain market functioning. Current research tests the stock returns behaviour of Sharī'ah-compliant Karachi Stock Exchange Meezan Index (KMI 30) under weak form efficiency. Based on the nature of data, i.e. time series, both linear and non-linear techniques are employed to assess market efficiency. The study results portray that KMI-30 is an inefficient market, and there is dependence in the series.
\end{abstract}

KAUJIE Classification: L24, L4, L31, V12

JEL Classification: C1, G21, G24

(C) 2020 JIBM. All rights reserved.

\section{INTRODUCTION}

Fama (1965) is considered the one who originally introduced the term of Efficient Market Hypothesis (EMH) for the very first time. Subsequently, it became the central premise to explain market functioning. EMH is sustained by the principle of rationality, where all information is included in prices. Therefore, investors are unable to generate any abnormal returns. The market tends to react instantaneously to new information as it becomes available (Fama, 1965). Since the market information arrives randomly, stock market returns remain unpredictable and exhibit a random walk. Theoretical foundations of EMH rests on three basic assumptions: first is complete rationality of market participants; second, allows for investors' bounded rationality; and third stresses on the role of rational arbitrageurs who would trade to profit on any mispricing and thus push prices back to their rational equilibrium. As a result, markets always remain efficient as the markets provide a self-corrective mechanism to reinforce rational equilibrium based on investors' sentiment and economic fundamentals. Fama unveiled three stock market efficiency forms, and these are weak, semi-strong, and strong form efficiencies. Fernando and Guanasekara (2018) posit that a market cannot be semi-strong or strong form efficient if it is not weak-form efficient. Therefore, a market

\footnotetext{
${ }^{*}$ Corresponding author: Naveed ul Hassan

${ }^{\dagger}$ Email: naveed.hassan@vu.edu.pk
} 
should be analyzed for weak-form efficiency first.

Studies conducted in the past have revealed contradictory results, i.e. both in favour (Alkhazali, 2011; Al-Khazali et al., 2014a; Asiri, 2008) and against (Ito, 1999; Menkhoff, 2010, Metghalchi et al., 2012; Omran \& Farrar, 2006) the proponents of EMH. Thus, it is understandable that research on market efficiency is not conclusive to date (Peon, Antelo \& Calvo, 2019). The world became more interested in Islamic capital markets for investment and diversification purpose after the global financial crisis (GFC) of 2008 (Al-Khazali et al., 2014b; Arouri \& Teulon, 2014; Azmat et al., 2014), due to its resilient behaviour during the financial crisis (Jawadi et al., 2014). Initially, the literature on Islamic finance was more concerned with analyzing financial principles, as Alhabshi (1994) explored Islamic financial markets' particularities about rules and regulations. While the other strand of research explored was related to compliance with Islamic principles (Anwar \& Tahir, 1995) and Sharí'ah-compliant instruments (Ahmad, 1997). However, Islamic markets' efficiency is rarely studied (Girard \& Hassan, 2008; Kok et al., 2009).

The current study is focused on analyzing the efficiency of Karachi Stock Exchange Meezan Index 30 (KMI 30). The KMI 30 comprise thirty companies fulfilling the Islamic Shar''ah criteria. The index includes non-financial, low-debt, social-ethical stocks that exclude all those stocks or industrial groups that are incompatible with Islamic principles. This index is based on six Sharī'ah screen filters. Firstly, this index excludes all those stocks which violate any principle of Sharī'ah, for example, companies involved in activities like; alcohol, arms manufacturing, banking or interest-based income, life insurance, gambling, pork; all those companies whose gross debt ratio (interest-bearing) is more than $37 \%$, noncompliant investment to total assets ratio is more than $33 \%$, non-compliant income to total revenue exceed $5 \%$, illiquid to total assets is less than $25 \%$, whereas the market price of the stock not equal to or less than net liquid assets per share. The current study employed both linear and non-linear tests to check dependence of KMI 30 index.

Since the inception of the EMH, it is considered central to examine financial markets' behaviour. Many studies for analyzing the efficiency of conventional stock markets have been conducted in the past (Alkhazali, 2011; Al-Khazali et al., 2014; Asiri, 2008; Menkhoff, 2010, Metghalchi et al., 2012; Omran \& Farrar, 2006). But in the recent financial crisis, the Shari' 'ah-compliant stocks outperformed the conventional stock, therefore, investors started investing in the Islamic stock markets for diversification purpose. Although there has been a significant development in Islamic finance, very little literature is available on testing the market efficiency of Shar'̄'ah-compliant stocks (Jawadi et al., 2015). Although more recently, some studies, including (Al-Khazali \& Mirzaei, 2017; Ali et al., 2018), investigated the stock market efficiency of Sharīa Compliant indices. Nevertheless, these studies were conducted on the Islamic Indices of developed countries, and Islamic Indices of developing countries like Pakistan has been ignored. Therefore this study is a valuable addition to the existing literature. Further, the studies used different statistical techniques and found different results in other markets. Thus, with the increasing trend of investing in Islamic indices, there is a need to further probe the efficiency of the Islamic index by using sophisticated econometric techniques catering to both linear and non-linear dependence in KMI 30 Index. Thus, the 
current study contributes to the literature by implementing both linear and non-linear tests to ensure the study's robustness. Additionally, this data covers the period during which Pakistan's Stockmarket was reclassified into the MSCI emerging index in May 2017 (MSCI 2020), which has been ignored in the literature.

The study's objective is to examine the efficiency of the KMI 30 Index by incorporating a series of linear and non-linear tests. The current study inspects whether a change in the stock prices of the Sharī'ah-compliant Index (KMI30) is independent? The evidence of such predictability violates the weak form of EMH. The answer to this question has serious implications for investors, traders and financial analysts for portfolio diversification. In markets that are not efficient, there is a possibility of earning abnormal returns.

\section{LITERATURE REVIEW}

Traditionally, market efficiency is tested using numerous methods and procedures for testing the independence of stock returns. The most commonly used methods for testing the linear independence of returns is the autocorrelation test (Guidi et al., 2011; Hamid et al., 2010). However, various other linear tests like the run test (Guidi et al., 2011; Hamid et al., 2010; Urrutia, 1995), variance-ratio test (Huang, 1995, Lo \& MacKinlay, 1988) and unit root tests (Hamid et al., 2010) have also been used in the literature. Amini et al. (2010) pointed out that the linear tests may not pick up the time series's non-linear dependence. Subsequently, loads of tests for examining non-linear structure of returns series exploded in the literature ${ }^{1}$. There are two broad categories of non-linear tests. The first type of tests includes bispectrum test (Hinich, 1982), bi-correlation test (Hinich, 1996), neural network (Lee et al., 1993) and Broock-Dechert-Scheinkman (BDS) test (Broock et al., 1996). Although these tests have the tendency to tackle non-linear aspect of series, however, in case if the null hypothesis is rejected, these tests fail to provide information through which it can be assessed which type of non-linear dynamics is currently present in the series. The second type of tests involves, LM or Wald test like ARCH process (Engle, 1982; Luukkonen et al., 1988).

Hassan (2002) used linear tests like variance ratio, auto-correlation and Dickey-Fuller test to examine the efficiency of the Dow Jones Islamic Index (DJIM) using data for the period of 1996-2000 and found the DJIM index is efficient. Hussein (2007) found abnormal returns in the DJIM index being efficient from 1996 to 2003. Many of the past studies compared Sharī'ah-compliant and conventional stock indices, and these studies have reported that Sharī'ah-compliant stocks perform better than their conventional counterparts (Abdullah et al., 2007; Elfakhani et al., 2005; Girard \& Hassan, 2008; Hayat \& Kraeussl, 2011). Rizvi et al. (2014) analyzed Malaysia, Turkey and Indonesian Islamic markets to their conventional counterparts and found Islamic markets are weak-form efficient. Mensi et al. (2017) studied ten sectoral Islamic indices and found efficiency levels to be time-varying. Thus, the efficiency of the Islamic market was seldom studied and provided controversial results (Jawadi et al., 2015). These inconclusive results regarding the efficiency of Islamic markets motivated to probe Islamic stock markets further.

${ }^{1}$ Complete review of nonlinear tests was conducted by Tsay (2005) 
Akbar and Baig (2010) used the data of Pakistan Stock Exchange (PSX) (formerly known as Karachi stock exchange) covering the period of June 2004 to June 2007 and it was established that the null hypothesis of semi-strong form is not supported. While Chakraborty (2006) found that the market is in-efficient. Rabbani et al. (2013) used linear tests and found that the KSE100 index is in-efficient. More recently, Ali and Sharif (2018) studied PSX, they distributed the data into two phases, i.e. before and after integration of Lahore Stock Exchange (LSE) and Islamabad Stock Exchange (ISE) with Karachi Stock Exchange (KSE) to form PSX. They found that the stock market in Pakistan showed no signs of efficiency.

Most of the studies employing non-linear tests found the presence of non-linear dependence structure. Findings emphasized that non-linearity is a real phenomenon with respect to international stock markets. The rich amount of literature provides evidence of possible deviation of prices and returns. Although different data generator processes have been followed, still, none of them can accept or reject the EMH phenomenon fully. The literature on testing the dependence of Sharī' ah Compliant indices or Islamic Indices is scarce. Thus, dependence, i.e. linear, non-linear, time or any other dependence, justifies the need for further analysis.

\section{RESEARCH DESIGN AND METHODOLOGY}

The current study examines the stock market efficiency of KMI30. Therefore, this study considers the positivistic view of what constitutes knowledge with respect to the epistemological assumption. The data of KMI 30 is secondary in nature, and its investigation is assumed to be an objective phenomenon. The current study adopts both linear and non-linear quantitative data analysis techniques so that the findings can be generalized. Thus, in accordance with ontology and epistemology, the methodological choice for the study becomes quite clear. Therefore, quantitative research methods based on equity Indices data is employed. Further, the nature of the study is explanatory, which justifies the use of quantitative research methodology.

A market is presumed weak-form efficient under random walk phenomena. Various tests of independence inspect whether the random walk hypothesis (RWH) is followed by prices or not. Three tests, including runs test, autocorrelation test and VR test, are implemented for testing the linear dependence of the index returns series, while two non-linear tests, including BDS test and Engle LM test, capture non-linear dependence. If returns are independent and indicating no sign of dependence throughout the sample, then in such case, markets are considered as Efficient. Contrary to this, markets are inefficient, signifying the absence of independence throughout the sample.

\section{Linear Tests}

\section{Autocorrelation test}

This test is most commonly used for testing independence of variable or a time series. Existence of autocorrelation in the data reveals that today's return is dependent on its lagged return. Thus series is not independent. Autocorrelation $(\rho k)$ is deemed to exist if the covariance and correlation and between the disturbances are not all non-zero. 
We may write it as:

$\left(i \operatorname{Cov}\left(\varepsilon_{i}, \varepsilon_{j}\right)\right)=\theta_{i j}$

Where ' $i$ ' and ' $j$ ' are not equal, and $\varepsilon_{t}$ is the error term of every $i^{t h}$ observation $H_{0}: \rho=0$ or

$H_{0}$ of autocorrelation test show independence or postulate that the series follows a random walk, where autocorrelation may be of two types, i.e. positive autocorrelation where $(\rho>0)$ and negative autocorrelation where $(\rho<0)$.

\section{Runs Test}

The run test works on the non-parametric dataset, and it traces the independence of a time series data. A run is known to be succession of identical symbols, which can be either negative or positive and is followed by different symbols; or in other words, a run may be based on series of positive or negative returns. This test ignores any sign (positive or negative) and chose the symmetry of the sign. This test declares a time series as random if the number of Run equates expected number of Run

$H_{0}$ series follow random behaviour

Following is the formula used for calculating the number of runs

$$
E(\mu)=\frac{2 P N(P+N)}{P+N}
$$

Whereas the variance of the runs is calculated as;

$$
\theta^{2}=\frac{2 P N(2 P N-P-N)}{(P+N)^{2}(P+N-1)}
$$

Where; positive run $=p$ and negative run $=N$.

\section{Variance Ratio Test}

Lo and Mackinlay (1998) were the pioneers of the variance ratio test (VR test). This test is coined as a primary tool for detecting serial correlation in a series, especially in stock return. Hoque et al. (2007) affirmed the VR test as the most important tool for testing the RWH. VR test implies that if a stock price follows a RW, then the variance of the k-period return is equal to $\mathrm{k}$ times the variance of the one-period return. Lo and MacKinlay (1988) also provided a complete mechanism for hypothesis testing, which relied on VR(k) in the context of a single variance ratio.

The $H_{0}$ of this test is

Variance $=1$ for all ks

In case of uncorrelated errors with robust heteroscedasticity statistics

$$
M_{2}(k)=\frac{V R(x-k)-1}{\Phi *(k)^{2}}
$$


Null hypothesis $\left(H_{0}\right)$ work under normal distribution where $V(K)=1$

$$
\begin{gathered}
\Phi *(k)^{2}=\sum_{k-1}^{j=1}\left[\frac{2(k-j)}{k}\right]^{2} \delta(j) \\
\delta(j)=\left\{\sum_{t=j+1}^{T}\left(x_{t}-\hat{\mu}\right)^{2}\left(x_{t-j}-\hat{\mu}\right)^{2}\right\}\left\{\left[\sum_{t=j}^{T}\left(x_{t}-\hat{\mu}\right)^{2}\right]^{2}\right\}
\end{gathered}
$$

\section{Non-Linear tests}

The tests mentioned above are helpful for examining the linear dependence of a returns series; however, these tests are unable to detect the non-linear dependence. Recent literature has emphasized non-linear testing dependence as it is revealed by studies that there is presence of non-linear dependence where the linear tests found independence in a series (Alagidede, 2011; Caraiani, 2012; Hiremath \& Kamaiah, 2010; Lim \& Hooy, 2013). For non-linear testing dependence, the time series data is required to be pre-whitened through $\mathrm{AR}(\mathrm{p})$ process so that all linear correlations are removed from the series.

\section{Engle LM Test}

This test was developed by Engle in 1982 contains the property of detecting an ARCH disturbance in a series. In this test, firstly, the residuals generated through the pre-whitened $\mathrm{AR}(\mathrm{p})$ model are tested for presence of heteroscedasticity. Where e is the residuals, the LM statistics is computed through auxiliary regression.

$$
e_{t}^{2}=\alpha_{0} \sum_{t-1}^{p} \alpha_{i} e_{t-1}^{2}+v_{t}
$$

$\mathrm{H} 0$ is the independence of returns. If the null is rejected, it means data has ARCH/GARCH non-linear effects.

\section{The BDS test}

Broock et al. (1996) proposed a non-parametric test named as BDS test. This has the property of testing serial dependence (non-linear structure) of a time series or series of stock returns. The $\mathrm{H} 0$ of the process is independently identically distributed, whereas the alternate hypothesis states, "an indication that the model is misspecified" (Brock et al., 1996). BDS test is computed as follows;

$$
c_{m}(e)=\left(1 N^{2}\right) *=\sum_{i, j=1}^{T} Z\left(e\left|x_{i}-x_{j}\right|\right), i \neq j
$$

Where $\mathrm{Z}(\mathrm{e})=1$ and if

$$
\left[\left(e\left|x_{i}-x_{j}\right|\right)>0\right], 0 o M_{1}: x_{t}^{1}=x_{t}
$$


In the above equation; $\mathrm{t}$ denotes the number of observation, $\mathrm{X}$ is an index return series, $\mathrm{e}$ is distance, whereas $\mathrm{Cm}$ is a product of correlation integral form dimensions

$$
\begin{gathered}
M_{2}: x_{t}^{2}=\left(x_{t}-x_{t-1}\right) \\
M_{m}: x_{m}^{t}=\left(x_{t} \ldots \ldots x_{t+m-1}\right)
\end{gathered}
$$

Where $\mathrm{z}$ counts the distances between the distance points of e. Brock demonstrated that;

$$
\left|c_{n}(e, T)-c_{1}(e, t)^{n}\right| * \sqrt{T}
$$

With normal distribution with a mean of 0 , the BDS statistics, W, is given by

$$
W_{n}(e, T)=\left|c_{n}(e, T)-c_{1}(e, t)^{n}\right| * \sqrt{\frac{T}{S_{n}(e, T)}}
$$

Here, $S N(e, T)=\theta$ of $\mathrm{Cm}$, the developer of the test recommended iteration of test at a different value, e.g. to $0.5 \theta, 1 \theta, 1.5 \theta$ and $2 \theta$ for better results.

\section{EMPIRICAL EVIDENCE}

\section{Data}

The sample data consist of daily prices of KMI30, which is considered to be a representative Islamic Index in Pakistan. The data comprises May 15, 2013, to July 3, 2019, and is obtained from the Standard Capital Securities Limited website. If we look at the graph, it is evident that the index prices have a persistent pattern.

\section{LOG CLOSE}

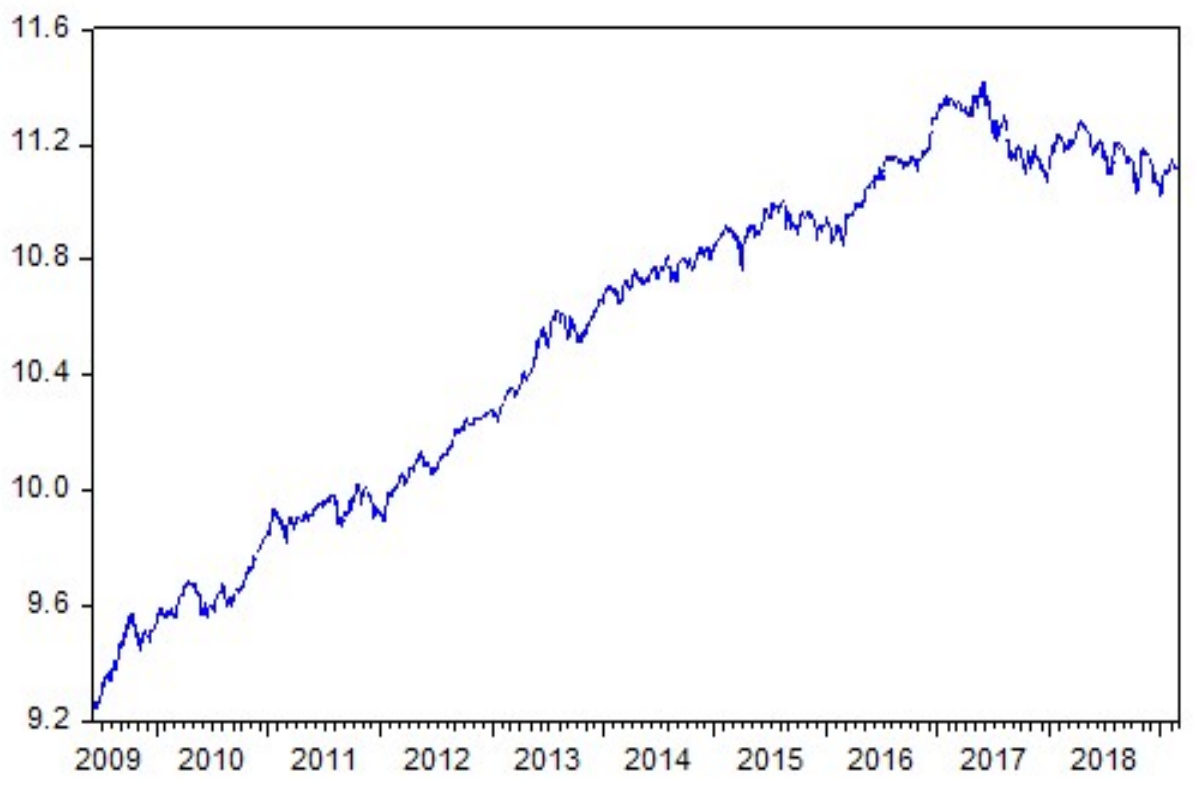

FIGURE 1. KMI-30 index series 
By taking the first difference of the logarithm of prices, a return series is generated. This process transforms the data, which is plotted in figure 1, to one period return. The newly generated return series is plotted in figure 2 .

$$
r_{t}=\ln \frac{p_{t}}{p_{t-1}}
$$

The visual interpretation of the returns series indicates that the returns precisely oscillates around zero. It can be visually observed that the returns vary over time. However, the magnitude of change in return and the sequence of positive and negative return seems to be random. Still, the tendency of positive returns, which is followed by positive returns and vice versa, appears to be weak, which is a sign of weak autocorrelation. Further, the variation has increased over time.

\section{LN RETURN}

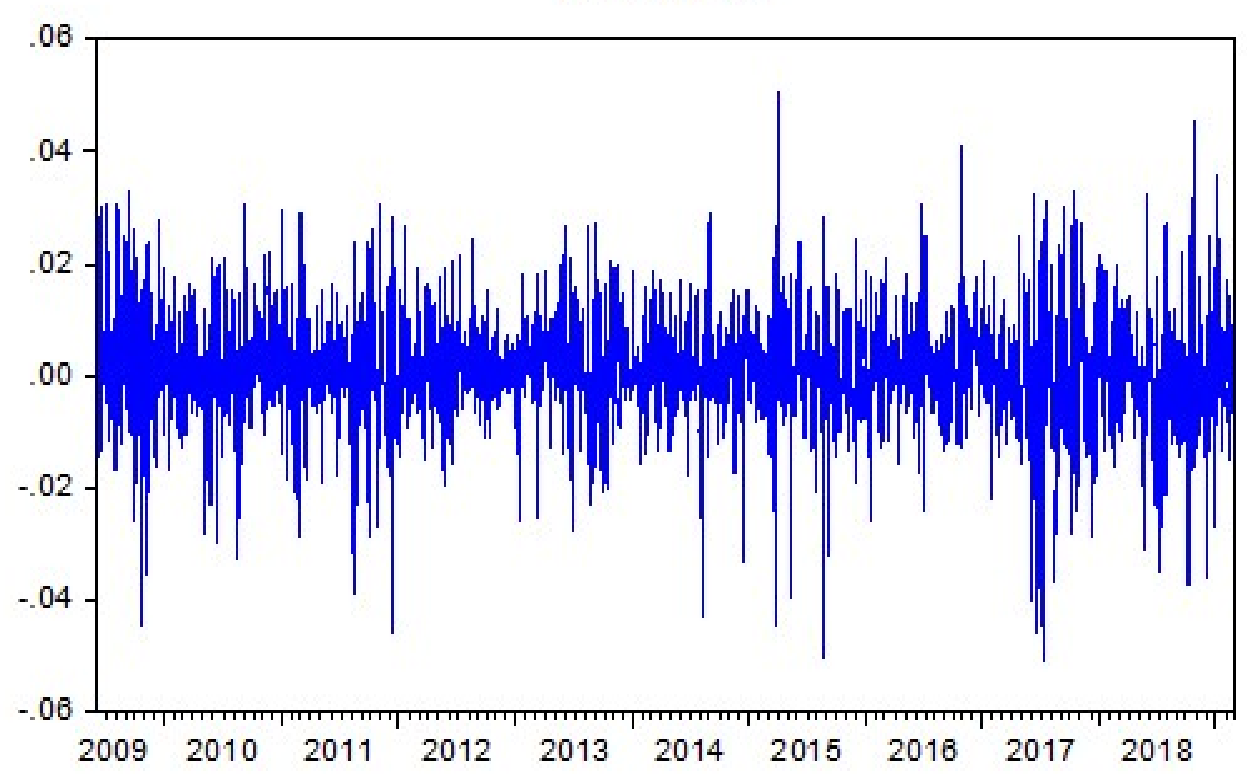

FIGURE 2. KMI-30 return series

Table 1 demonstrates the descriptive statistics of the KMI-30 daily returns series. The mean of returns is $0.0766 \%$, with a maximum of $5.0519 \%$ return and a minimum of $-5.1108 \%$ return. The series is negatively skewed, which implies that there is a long left tail. Further, the value of kurtosis is $>3$; thus, the returns' distribution is leptokurtic. The Jarque-Berra test is significant at $1 \%$, which shows strong signs of the non-normal distribution of the data. Finally, the value of standard deviation, which is also considered the measure of volatility, is $1.0614 \%$, 
TABLE 1

Descriptive Statistics

\begin{tabular}{ll}
\hline \hline & Returns \\
\hline Mean & 0.000766 \\
Median & 0.000439 \\
Std. Dev. & 0.010614 \\
Jarque-Bera & 602.1484 \\
Maximum & 0.050519 \\
Minimum & -0.051108 \\
Probability & $\hat{\text { Ăă } 0.000000 * * *}$ \\
Skewness & -0.230329 \\
Kurtosis & 5.403505 \\
Sum & 1.849554 \\
Sum Sq. Dev. & 0.271731 \\
Observations & 2413 \\
\hline
\end{tabular}

Jarque-Bera statistics. $* * *$ and $* * \bar{*}$ denotes the significance level of $10 \%, 5 \%$ and $1 \%$ respectively

\section{Stationarity}

Normally, the stock price series contains unit root which is a sign that the mean and variance of the series is not constant. This problem of price data is tackled by calculating the returns as per equation 13, i.e. logarithmic difference of lagged prices. This process converts the non-stationary with a unit root to a stationary process that does not contain a unit root. This phenomenon is confirmed through the augmented Dicky-Fuller test, which assumes that the series has a unit root. Table 2 presents the results of the augmented Dicky Fuller test (ADF). The results portray that the null hypothesis is accepted for price series, indicating that the series is non-stationary, whereas; it is rejected for returns series(differenced data), which suggests that the series is stationary.

TABLE 2

Augmented Dickey-Fuller

\begin{tabular}{lllll}
\hline \hline Augmented Dickey-Fuller & \multicolumn{2}{l}{ Price Level-Random Walk } & \multicolumn{2}{l}{ Returns-Random Walk } \\
\hline & t-statistics & Prob-value & t-statistics & Prob-value \\
\hline Full Sample & -2.356904 & 0.1544 & -44.59622 & $0.0001 * * *$ \\
\hline Null Hypothesis: Series has a unit root, ${ }^{* * *}, * *$ and & $*$ indicate a significance level of $1 \%, 5 \%$ and $10 \%$
\end{tabular}

\section{Independence Test}

The random walk model is tested by testing the returns for independence. The results of the linear and non-linear tests used in the study are presented in this section.

\section{Linear Tests}

Figure 3 demonstrates the autocorrelation co-efficient and p-values of KMI-30 for the first 20 
lags. The autocorrelation has been tested up to 20 lags, and it shows positively significant autocorrelation where the autocorrelation starts from 0.122 . From the results, it is found that the serial correlation being detected in the series is the consequence of the AR(1) process. This indicates existence of autocorrelation in index series. This also sign that the factors which affect the stock prices are likely to be in adjacent periods. This also provides strong evidence that the series is non-stationary. So it is concluded that there is dependence in the stock prices. Thus, the prices can be predicted, which is against the EMH. Therefore, it can be stated that EMH doesn't hold in KMI-30.

\section{LN RETURN}

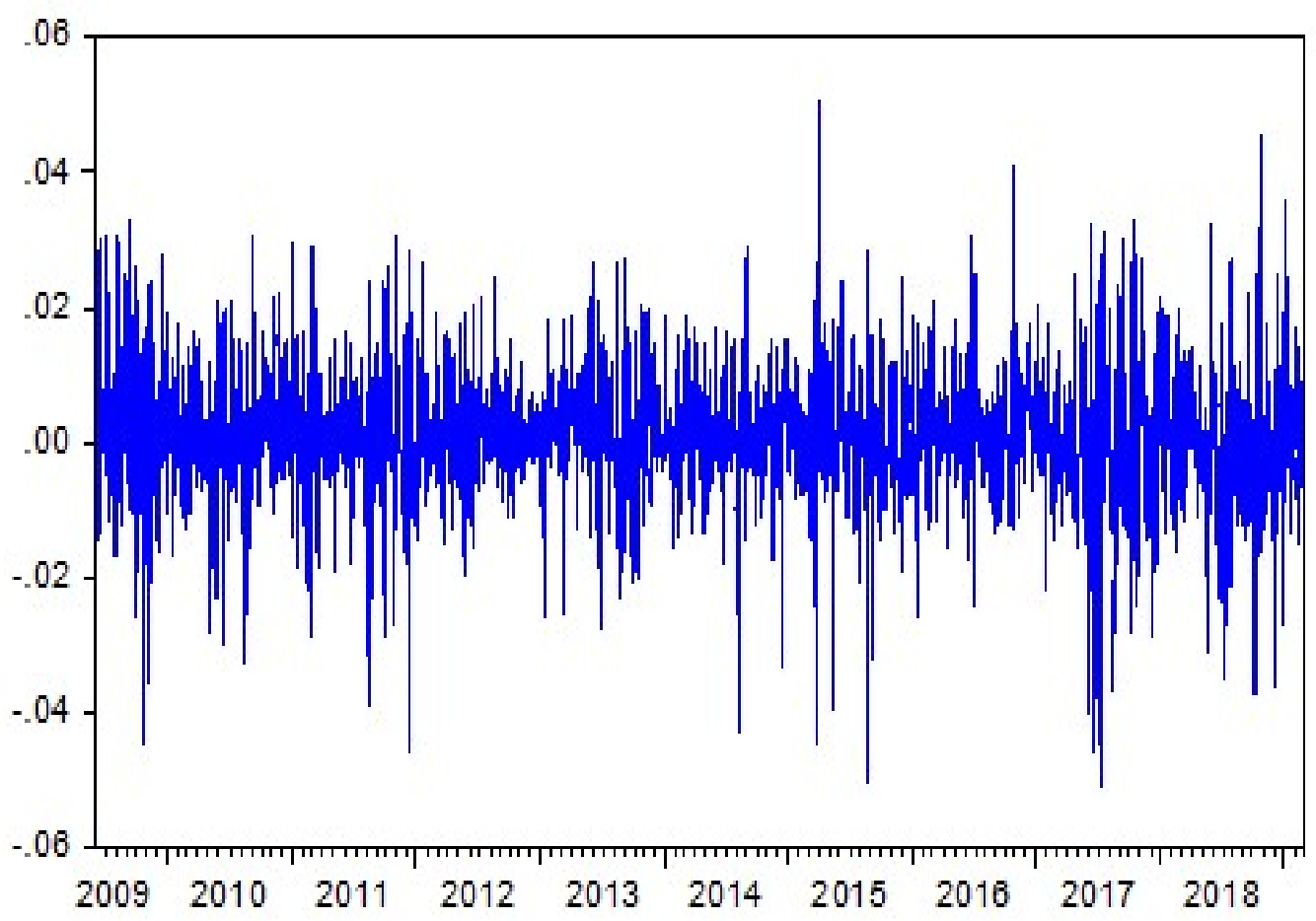

FIGURE 3. Correlogram

\section{RUNS Test}

Table 3 represents results of run tests of KMI30. This test examines the existence of serial correlation in data. This test suggests that if $p$-value is sufficiently small, say, less than .05 , it rejects the null of no randomness. It concludes that the series does not alternate enough (too few runs) or alternates too much (too many runs). From the results, it is proved to be statistically significant at $1 \%$ significance level. Thus, it is concluded that the sample is not independent. Therefore EMH does not hold. The results of the Runs test are consistent with that of autocorrelation. 
TABLE 3

RUNS Test

\begin{tabular}{ll}
\hline \hline Runs Test Results for Returns \\
\hline Number of obs & 2414 \\
Number above cutoff & 1397 \\
Number below cutoff & 1017 \\
Number of runs & 16 \\
E(R) & 1178.091 \\
Stdev(R) & 23.952 \\
Z-value & -48.517 \\
p-value (2-tailed) & $0.0000^{* * *}$ \\
\hline \hline
\end{tabular}

\section{Variance Ratio Test}

In Table 4, the results of the VR test are presented. The periods range from 2-16. As per the Null of VR test, returns possess uncorrelated increments. These ratios are dependent on autocorrelation, where deviation from unity is considered a sign of autocorrelation. The test statistics of variance ratio is equal to unity and statistically significant, which indicates dependence in the series. The full sample period of KMI-30 shows a significant positive correlation of all K's tested at $1 \%$ confidence. Thus, EMH does not hold.

TABLE 4

Variance Ratio Test

\begin{tabular}{lllll}
\hline \hline Joint Tests & & Value & Df & Probability \\
\hline Max $|\mathrm{z}|($ at period 2)* & 13.41292 & 2412 & $0.0000^{* * *}$ \\
\hline Individual Tests & & & & \\
\hline Period & Var. Ratio & Std. Error & z-Statistic & Probability \\
\hline 2 & 0.569688 & 0.032082 & -13.41292 & $0.0000^{* * *}$ \\
4 & 0.273693 & 0.055382 & -13.11446 & $0.0000^{* * *}$ \\
8 & 0.136534 & 0.080695 & -10.70033 & $0.0000^{* * *}$ \\
16 & 0.072262 & 0.113652 & -8.162990 & $0.0000^{* * *}$ \\
\hline \hline
\end{tabular}

Null Hypothesis: RETURNS is a martingale.

The results of all linear tests are similar for KMI-30. All the tests, i.e. autocorrelation, Runs test, and VR test, are positive and statistically significant. The alternate tests confirm the robustness of our results.

\section{Non-Linear Tests}

For further robustness of the study findings, a non-linear empirical investigation is also conducted. Studies have revealed that if the stock returns have autocorrelation, it is impossible to detect non-linearity structure from the original data. In this study, it is evident through linear tests that there are significant autocorrelation structures found in the full sample series. 
Figure 3 demonstrates the Ljung-Box statistics applied to the raw data to detect the series's linear dependence. The Q-statistics are significant at lag 1-20, and there is a very slow decay in the autocorrelation function. The slow decline in autocorrelation signifies a non-stationary and trend in the series. This concludes that there is a linear temporal relationship in stock returns. Therefore, for examining non-linear dependence in returns, it is important to remove the linear dependence from the series through the pre-whitening procedure.

Results of figure 4 portray the AR(p) model and diagnostics and show that linear structures have been eliminated. Now, the residuals generated through AR(1-4) model are tested for linearity in the KMI-30 series. The AC and PAC show no significant correlation with p-value $>0.05$; thus, it can be inferred that the linearity from the data has been removed, and the time series is white noise. The values of $\mathrm{AC}$ are checked up to $20 \mathrm{lag}$, and there is no auto found. Using AIC, BIC and Hannan-Quiin 4 lags are considered the best parsimonious model for the KMI-30 series, and all the Q-stats have become insignificant. However, this lack of significance does not imply that the series behave purely random. Therefore, the BDS and Engle LM tests are performed on the AR(1-4) model residuals.

\section{LN RETURN}

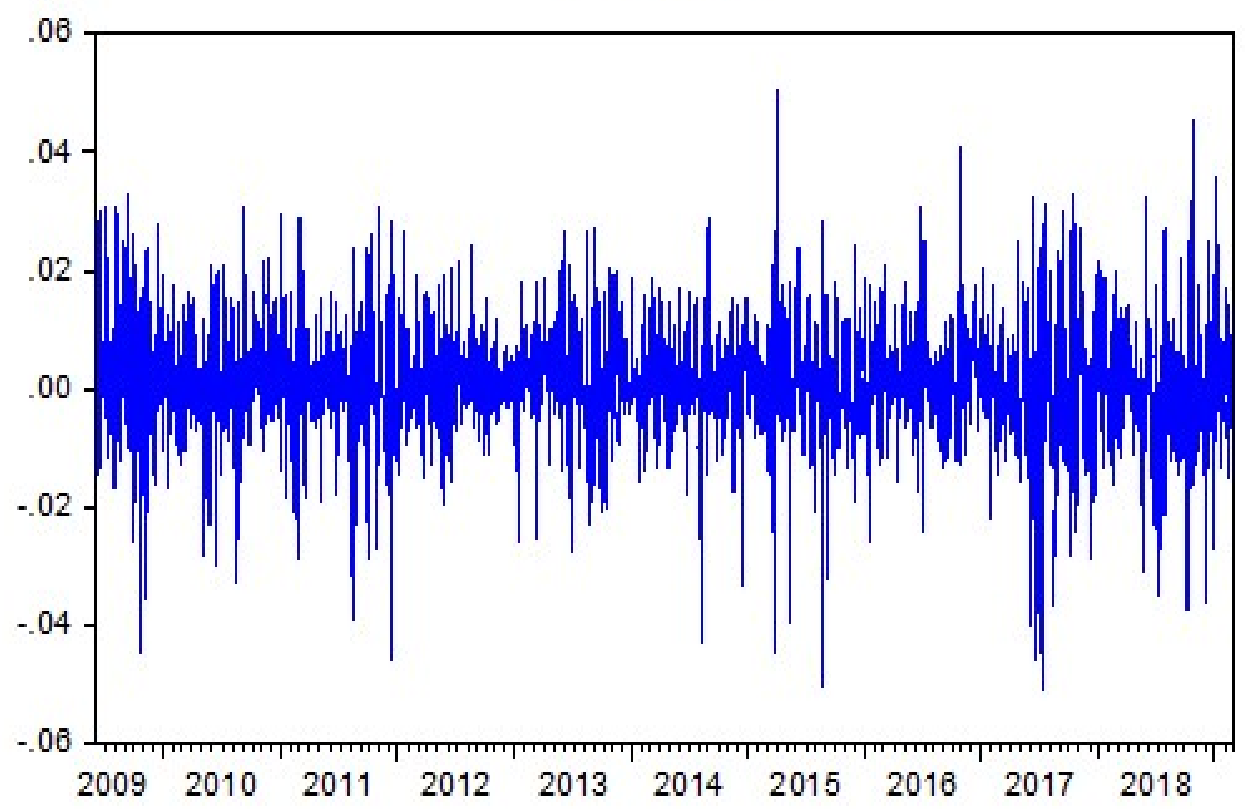

FIGURE 4. Correlogram II

\section{BDS Test}

This test examines the presence of non-linear dependence in data series. To conduct this test, firstly, linear dependence is being removed through the pre-whitened procedure. Table 5 portrays BDS test results, which posit that all dimensions used in the analysis are positive and significant at $1 \%$. This is a clear indication of strong evidence of non-linear dependence in returns of KMI 30. 
TABLE 5

BDS Test for Returns

\begin{tabular}{|c|c|c|c|c|c|c|c|c|c|}
\hline \multirow{2}{*}{$\begin{array}{l}0.5 \text { level of deviation } \\
\text { BDS }\end{array}$} & & & & \multicolumn{6}{|c|}{1 level of deviation } \\
\hline & & & & Normal & Bootstrap & BDS & & & Bootstrap \\
\hline Dimension & tatistic & Std. Error & z-Statistic & Prob. & Prob. & Statistic & Std. Error & z-Statistic & Prob. \\
\hline 2 & 0.006702 & 0.000932 & 7.191195 & $0.0000 * * *$ & $0.0000 * * *$ & 0.013996 & 0.001809 & $0.0000 * * *$ & $0.0000 * * *$ \\
\hline 3 & 0.007093 & 0.000688 & 10.31268 & $0.0000 * * *$ & $0.0000 * * *$ & 0.025531 & 0.002367 & $0.0000 * * *$ & $0.0000 * * *$ \\
\hline 4 & 0.004463 & 0.000381 & 11.70829 & $0.0000 * * *$ & $0.0000 *$ & 0.027970 & 0.002323 & $0.0000 * * *$ & $0.0000 * * *$ \\
\hline 5 & 0.002447 & 0.000185 & 13.21796 & $0.0000 * * *$ & $0.0000 * * *$ & 0.026117 & 0.001996 & $0.0000 * * *$ & $0.0000 * * *$ \\
\hline 6 & 0.001291 & 8.33E-05 & 15.50672 & $0.0000 * * *$ & $0.0000 * * *$ & 0.022902 & 0.001587 & $0.0000 * * *$ & $0.0000 * * *$ \\
\hline Raw epsilon & 0.005319 & & & & & 0.010638 & & & \\
\hline Pairs within epsilon & & 1027208. & V-Statistic & 0.322029 & & & 1846150. & & 0.578767 \\
\hline Triples within epsilon & & $7.16 \mathrm{E}+08$ & V-Statistic & 0.125729 & & & $2.16 \mathrm{E}+09$ & V-Statistic & 0.378550 \\
\hline
\end{tabular}

Statistics. $* * *, * *$ and $*$ indicate significance level of $1 \%, 5 \%$ and $10 \%$.

\section{ARCH LM Test}

Results of LM tests reveal the existence of ARCH effect. This test is applied to the residuals of pre-whitened series. The p-value of all computed lags is less than 0.05 ; thus, rejecting the series's Null hypothesis of being i.i.d. It concludes existence of ARCH effect. Thus, there is no independence in returns.

TABLE 6

LM Test for Autoregressive Conditional Heteroskedasticity (ARCH)

\begin{tabular}{llll}
\hline \hline lags(p) & Chi2 & Df & Prob > chi2 \\
\hline 1 & 62.270 & 1 & $0.0000^{* * *}$ \\
2 & 98.930 & 2 & $0.0000^{* * *}$ \\
3 & 102.888 & 3 & $0.0000^{* * *}$ \\
4 & 104.011 & 4 & $0.0000^{* * *}$ \\
5 & 130.793 & 5 & $0.0000^{* * *}$ \\
6 & 145.341 & 6 & $0.0000^{* * *}$ \\
7 & 144.249 & 7 & $0.0000^{* * *}$ \\
H0: & \multicolumn{4}{l}{ no ARCH effects; H1: ARCH(p) disturbance, }
\end{tabular}

\section{Conclusion}

The concept of market efficiency coined by Eugene Fama was well versed and accepted in the 1970s. At that time majority of the studies concluded that EMH holds. However, since then, many studies have argued against this concept and have found significant inefficiencies. This study has performed the tests for testing the independence of stock returns. The aim was to investigate whether EMH holds. Since the global financial crises, the Islamic equity Indices have been central to the investors, financial analysts and researchers. The studies in religion-based indices promulgate after global financial crises of 2007-2008. Although it is found that there is a significant development in field of Islamic finance, very little literature is available on testing the Islamic stock Indices' market efficiency (Al-Khazali et al., 2016; Jawadi et al., 2015). Further, the potential interest of international portfolio investors towards Sharī'ah-compliant stocks has increased over the decades. Therefore, assessment of such 
markets efficiency is relevant for investors, academicians and regulators. The battery of linear and non-linear tests are conducted to examine the independence of stock returns.

The runs and VR tests have suggested that the KMI-30 is an inefficient market because there is dependence in the series. Thus, it can be inferred that stocks' prices are predictable, and investors can generate more than normal returns. Further, to test the non-linear structure of time series. The AR model is used for filtering results by removing all linear correlations from the series. Lim and Hooy (2013) argued that the AR filter might remove the linearity from the series. However, there may still be heteroskedasticity in the series. Therefore nonlinear tests, including BDS and Engle LM tests, are applied, which also revealed dependence in the stock returns. Thus, inferring that EMH does not hold. The same was the findings of (Al-Khazali et al., 2016). They investigated nine Sharī'ah-compliant indices comprised of different regions and countries and found that Islamic stocks indices are inefficient.

Similarly, Alsayed (2016) contended that the four DJ Islamic indices show no market efficiency signs. Further, the results are consistent with the previous studies conducted in Pakistan (Shamshir et al., 2018; Rabbani et al., 2013; Ali \& Sharif, 2019). This indicates that there exist possibilities of earning abnormal profits by exploiting the information of the series.

\section{Implications}

Over the decades, EMH and RWH have been the central demise of financial literature. Wherein RWH proclaims that traders cannot beat the market. On the other hand, investors and policymakers prefer the markets to be efficient where the new information is adjusted quickly. The outside factors do not impact the value of stock prices. The present research results are helpful for the investors and market participants who are interested in investing in Islamic stocks. It is beneficial for stock analysts for making sound decision while forming investment portfolios. As the study, findings comprehend the behaviour of KMI30 market, the findings of the study also has implication regarding capital allocation within Islamic investing, which contributes to the country's economic development. Additionally, this study has theoretical implications for "Islamic regulators and scholars because of the issue of efficiency, which falls under the proponent of "maslaha" (Alsayed, 2016).

\section{REFERENCES}

Abdullah, F., Hassan, T., \& Mohamad, S. (2007). Investigation of performance of Malaysian Islamic unit trust funds: Comparison with conventional unit trust funds. Managerial Finance, 33(2), 142-153. doi: https://doi.org/10.1108/03074350710715854

Ahmad, A. (1997). Towards an Islamic financial market: A study of Islamic banking and finance in Malaysia (No. 45). Islamic Research and Training Institute, Jeddah, KSA.

Akbar, M., \& Baig, H. H. (2010). Reaction of stock prices to dividend announcements and market efficiency in Pakistan. Lahore Journal of Economics, 15(1), 103-125. doi: https://doi.org/10.35536/lje.2010.v15.i1.a5

Alagidede, P. (2011). Return behaviour in Africa's emerging equity markets. The Quarterly Review of Economics and Finance, 51(2), 133-140.

doi: https://doi.org/10.1016/j.qref.2011.01.004 
Alhabshi, S. O. (1994). Development of capital market under Islamic principles. Paper presented at the: Conference on Managing and Implementing Interest-Free Banking/Islamic Financial System, Kuala Lumpur.

Ali, A., \& Sharif, S. (2019). Stock market efficiency: The Pakistan stock exchange merger. Afro-Asian Journal of Finance and Accounting (AAJFA).

Ali, S., Shahzad, S. J. H., Raza, N., \& Al-Yahyaee, K. H. (2018). Stock market efficiency: A comparative analysis of Islamic and conventional stock markets. Physica A: Statistical Mechanics and Its Applications, 503, 139-153.

doi: https://doi.org/10.1016/j.physa.2018.02.169

AlKhazali, O. (2011). Does infrequent trading make a difference on stock market efficiency? Evidence from the Gulf cooperation council (GCC) countries. Studies in Economics and Finance, 28(2), 96-110. doi: https://doi.org/10.1108/10867371111137102

Al-Khazali, O. M., Leduc, G., \& Alsayed, M. S. (2016). A market efficiency comparison of Islamic and non-Islamic stock indices. Emerging Markets Finance and Trade, 52(7), 1587-1605. doi: https://doi.org/10.1080/1540496X.2014.998572

Al-Khazali, O., \& Mirzaei, A. (2017). Stock market anomalies, market efficiency and the adaptive market hypothesis: Evidence from Islamic stock indices. Journal of International Financial Markets, Institutions and Money, 51, 190-208. doi: https://doi.org/10.1016/j.intfin.2017.10.001

Al-Khazali, O., Lean, H. H., \& Samet, A. (2014a). Do Islamic stock indexes outperform conventional stock indexes? A stochastic dominance approach. Pacific-Basin Finance Journal, 28, 29-46. doi: https://doi.org/10.1016/j.pacfin.2013.09.003

Alsayed, M. S. (2016). Testing stock market efficiency in the weak form: Evidence from the Dow Jones Islamic indices (Ph.D. dissertation). Faculty of Business, University of Wollongong, Dubai, UAE.

Amini, S., Hudson, R., \& Keasey, K. (2010). Stock return predictability despite low autocorrelation. Economics Letters, 108(1), 101-103. doi: https://doi.org/10.1016/j.econlet.2010.04.031

Anwar, M., \& Tahir, S. (1995). An Islamic perspective on capital markets and" Islamic" Securities in Malaysia [with Comments]. The Pakistan Development Review, 34(4), 865-878. doi: https://doi.org/10.30541/v34i4IIpp.865-878

Arouri, M., \& Teulon, F. (2014). Persistence of performance using the four-factor pricing model: Evidence from dow jones Islamic index. Journal of Applied Business Research (JABR), 30(3), 917-928. doi: https://doi.org/10.19030/jabr.v30i3.8577

Asiri, B. (2008). Testing weak-form efficiency in the Bahrain stock market. International Journal of Emerging Markets, 3(1), 38-53.

doi: https://doi.org/10.1108/17468800810849213

Azmat, S., Skully, M., \& Brown, K. (2014). The Sharī'ah compliance challenge in Islamic bond markets. Pacific-Basin Finance Journal, 28, 47-57.

doi: https://doi.org/10.1016/j.pacfin.2013.11.003

Broock, W. A., Scheinkman, J. A., Dechert, W. D., \& LeBaron, B. (1996). A test for independence based on the correlation dimension. Econometric Reviews, 15(3), 197-235. doi: https://doi.org/10.1080/07474939608800353 
Caraiani, P. (2012). Non-linear dynamics in CEE stock markets indices. Economics Letters, 114(3), 329-331. doi: https://doi.org/10.1016/j.econlet.2011.11.010

Chakraborty, M. (2006). Market efficiency for the Pakistan stock market: Evidence from the Karachi stock exchange. South Asia Economic Journal, 7(1), 67-81.

doi: https://doi.org/10.1177/139156140500700104

Elfakhani, S., Hassan, M. K., \& Sidani, Y. (2005). Comparative performance of Islamic versus secular mutual funds. Paper presented at the: 12th Economic Research Forum Conference, Cairo, Egypt.

Engle, R. F. (1982). Autoregressive conditional heteroscedasticity with estimates of the variance of United Kingdom inflation. Econometrica: Journal of the Econometric Society, 50(4), 987-1007. doi: https://doi.org/10.2307/1912773

Fama, E. F. (1965). The behavior of stock-market prices. The Journal of Business, 38(1), 34-105. doi: https://doi.org/10.1086/294743

Fernando, P. N. D., \& Gunasekara, A. L. (2018). Is the market efficiency static or dynamicEvidence from Colombo Stock Exchange (CSE). Kelaniya Journal of Management, 7(1), 13-25. doi: https://doi.org/10.4038/kjm.v7i1.7551

Girard, E. C., \& Hassan, M. K. (2008). Is there a cost to faith-based investing: Evidence from FTSE Islamic indices. The Journal of Investing, 17(4), 112-121.

doi: https://doi.org/10.3905/JOI.2008.17.4.112

Guidi, F., Gupta, R., \& Maheshwari, S. (2011). Weak-form market efficiency and calendar anomalies for Eastern Europe equity markets. Journal of Emerging Market Finance, 10(3), 337-389. doi: https://doi.org/10.1177/097265271101000304

Hamid, K., Suleman, M. T., Ali Shah, S. Z., Akash, I., \& Shahid, R. (2017). Testing the weak form of efficient market hypothesis: Empirical evidence from Asia-Pacific markets. International Research Journal of Finance and Economics, 58, 121-133.

doi: https://doi.org/10.2139/ssrn.2912908

Hassan, M. K. (2002). Risk, return and volatility of faith-based investing: the case of Dow Jones Islamic index. Paper presented at the: Proceedings of the Fifth Harvard University Forum on Islamic Finance, Harvard University, Cambridge, MA.

Hayat, R., \& Kraeussl, R. (2011). Risk and return characteristics of Islamic equity funds. Emerging Markets Review, 12(2), 189-203. doi: https://doi.org/10.1016/j.ememar.2011.02.002

Hinich, M. J. (1982). Testing for Gaussianity and linearity of a stationary time series. Journal of Time Series Analysis, 3(3), 169-176. doi: https://doi.org/10.1111/j.1467-9892.1982.tb00339.x

Hinich, M. J. (1996). Testing for dependence in the input to a linear time series model. Journal of Nonparametric Statistics, 6(2-3), 205-221. doi: https://doi.org/10.1080/10485259608832672

Hiremath, G. S., \& Kamaiah, B. (2010). Non-linear dependence in stock returns: Evidences from India. Journal of Quantitative Economics, 8(1), 69-85. doi: https://doi.org/10.21648/arthavij/2009/v51/i1/115429 
Hoque, H. A., Kim, J. H., \& Pyun, C. S. (2007). A comparison of variance ratio tests of random walk: A case of Asian emerging stock markets. International Review of Economics $\mathcal{E}$ Finance, 16(4), 488-502. doi: https://doi.org/10.1016/j.iref.2006.01.001

Huang, B. N. (1995). Do Asian stock market prices follow random walks? Evidence from the variance ratio test. Applied Financial Economics, 5(4), 251-256. doi: https://doi.org/10.1080/758536875

Hussein, K. A. (2007). Islamic investment: Evidence from Dow Jones and FTSE indices. Islamic Economics and Finance, 1, 387-401.

Ito, A. (1999). Profits on technical trading rules and time-varying expected returns: evidence from Pacific-Basin equity markets. Pacific-Basin Finance Journal, 7(3-4), 283-330. doi: https://doi.org/10.1016/S0927-538X(99)00008-6

Jawadi, F., Jawadi, N., \& Cheffou, A. I. (2015). Are Islamic stock markets efficient? A time-series analysis. Applied Economics, 47(16), 1686-1697.

doi: https://doi.org/10.1080/00036846.2014.1000535

Jawadi, F., Jawadi, N., \& Louhichi, W. (2014). Conventional and Islamic stock price performance: An empirical investigation. International Economics, 137, 73-87. doi: https://doi.org/10.1016/j.inteco.2013.11.002

Kok, S., Giorgioni, G., \& Laws, J. (2009). Performance of Sharī'ah-Compliant Indices in London and NY stock markets and their potential for diversification. International Journal of Monetary Economics and Finance, 2(3-4), 398-408.

doi: https://doi.org/10.1504/IJMEF.2009.029071

Lee, T. H., White, H., \& Granger, C. W. (1993). Testing for neglected non-linearity in time series models: A comparison of neural network methods and alternative tests. Journal of Econometrics, 56(3), 269-290. doi: https://doi.org/10.1016/0304-4076(93)90122-L

Lim, K. P., \& Hooy, C. W. (2013). Non-linear predictability in G7 stock index returns. The Manchester School, 81(4), 620-637. doi: https://doi.org/10.1111/j.1467-9957.2012.02303.x

Lo, A. W., \& MacKinlay, A. C. (1988). Stock market prices do not follow random walks: Evidence from a simple specification test. The Review of Financial Studies, 1(1), 41-66. doi: https://doi.org/10.1093/rfs/1.1.41

Luukkonen, R., Saikkonen, P., \& Terasvirta, T. (1988). Testing linearity against smooth transition autoregressive models. Biometrika, 75(3), 491-499.

doi: https://doi.org/10.1093/biomet/75.3.491

Menkhoff, L. (2010). The use of technical analysis by fund managers: International evidence. Journal of Banking E Finance, 34(11), 2573-2586.

doi: https://doi.org/10.1016/j.jbankfin.2010.04.014

Mensi, W., Hammoudeh, S., Nguyen, D. K., \& Kang, S. H. (2017). Global financial crisis and spillover effects among the US and BRICS stock markets. International Review of Economics $\mathcal{E}$ Finance, 42, 257-276. doi: https://doi.org/10.1016/j.iref.2015.11.005

Metghalchi, M., Marcucci, J., \& Chang, Y. H. (2012). Are moving average trading rules profitable? Evidence from the European stock markets. Applied Economics, 44(12), 1539-1559. doi: https://doi.org/10.1080/00036846.2010.543084 
Omran, M., \& Farrar, S. V. (2006). Tests of weak form efficiency in the Middle East emerging markets. Studies in Economics and Finance, 23(1), 13-26.

doi: https://doi.org/10.1108/10867370610661927

Peon, D., Antelo, M., \& Calvo, A. (2019). A guide on empirical tests of the EMH. Review of Accounting and Finance, 18(2), 268-295.

doi: https://doi.org/10.1108/RAF-02-2016-0031

Rabbani, S., Kamal, N., \& Salim, M. (2013). Testing the weak-form efficiency of the stock market: Pakistan as an emerging economy. Journal of Basic and Applied Scientific Research, 3(4), 136-142.

Rizvi, S. A. R., Dewandaru, G., Bacha, O. I., \& Masih, M. (2014). An analysis of stock market efficiency: Developed vs Islamic stock markets using MF-DFA. Physica A: Statistical Mechanics and its Applications, 407, 86-99. doi: https://doi.org/10.1016/j.physa.2014.03.091

Shamshir, M., Baig, M. J., \& Mustafa, K. (2018). Evidence of random walk in Pakistan stock exchange: An emerging stock market study. Journal of Economics Library, 5(1), 103-117.

Tsay, R. S. (2005). Analysis of financial time series (Vol. 543). John wiley \& sons. doi: https://doi.org/10.1002/0471746193

Urrutia, J. L. (1995). Tests of random walk and market efficiency for Latin American emerging equity markets. Journal of Financial Research, 18(3), 299-309.

doi: https://doi.org/10.1111/j.1475-6803.1995.tb00568.x 